\title{
PERANCANG BANGUN APLIKASI MOBILE PADA PLATFORM ANDROID BERBASIS HTML5 STUDI KASUS LAYANAN INFORMASI WEBSITE UNIPDU JOMBANG
}

\author{
Mita Septiana Chumairoh $^{1}$, Budiman ${ }^{2}$, Diema Hernyka Satyareni ${ }^{3}$ \\ Universitas Pesantren Tinggi Darul Ulum \\ Jombang, Indonesia \\ mitayin23l@gmail.com
}

\begin{abstract}
Abstrak
Perkembangan teknologi web saat ini banyak digunakan pengembang software, begitu juga di Unipdu. Kebutuhan menggunakan teknologi ini sangat dibutuhkan sebagai media layanan informasi berbasis web. Akan tetapi, dengan perkembangan teknologi mobile terutama Android yang banyak digunakan, layanan informasi yang sudah berjalan saat ini harus bisa mengikuti perkembangan teknologi mobile tersebut. Oleh karena itu, dibangunlah Aplikasi Web Mobile Android berbasis HTML5 dengan tujuan agar dapat memenuhi kebutuhan informasi yang dapat diakses melalui perangkat mobile. Aplikasi ini dilengkapi dengan notifikasi pengumuman untuk mahasiswa dan notifikasi pendaftaran online untuk admin PMB. Aplikasi mobile yang dibangun mengimplementasikan tiga teknologi yaitu HTML5, Hybrid Application yang digunakan untuk membangun aplikasi mobile di android, dan Google Cloud Messagging sebagai penyedia layanan cloud messaging yang digunakan untuk mengirim notifikasi ke perangkat android. Aplikasi ini berupa installer yang dapat diinstall di perangkat mobile android. Hasil uji coba aplikasi menyimpulkan bahwa HTML5 dapat diterapkan pada layanan informasi website Unipdu Jombang yang dapat berjalan pada platform android.
\end{abstract}

Kata Kunci : HTML5, Mobile Android, Hybrid Application, Google Cloud Messagging. 


\begin{abstract}
The development of web technology is currently widely used software developers, as well as in Unipdu. The need to use this technology is needed as a medium of web-based information services. However, with the development of mobile technology, especially Android which is widely used, the service information that is already running at this time should be able to follow the development of mobile technology. Therefore, built Web Applications Mobile Android-based HTML5 in order to meet the needs of information that can be accessed through mobile devices. The application comes with a notification announcements for students and online registration notification for admin PMB. Mobile applications that are built to implement the three technologies, namely HTML5, Hybrid Application used to build mobile applications on Android, and Google Cloud Messagging as a provider of cloud messaging service used to send notifications to your android device. This application can be installed in the installer android mobile devices. The trial results concluded that HTML5 applications can be applied to services Jombang Unipdu website information that can be run on android platform
\end{abstract}

Keywords: HTML5, Android Mobile, Hybrid Application, Google Cloud Messaggin 


\section{PENDAHULUAN}

Universitas Pesantren Tinggi Darul 'Ulum (UNIPDU) Jombang telah memiliki website yang dilengkapi dengan layanan informasi akademik yang dapat diakses melalui web browser baik itu desktop browser maupun mobile browser. Adanya website dirasa masih kurang efektif karena hasil survey membuktikan bahwa mahasiswa jarang sekali membuka website untuk mencari informasi, hal ini terbukti mahasiswa kurang update dalam mendapatkan informasi akademik Unipdu..

Untuk mengatasi hal tersebut perlu adanya pengembangan ke arah mobile application. Dengan adanya hybrid application yang dibangun dengan HTML5 dirasa sangat cocok untuk mengembangkan website ke arah mobile. Aplikasi nantinya akan terpasang pada perangkat mobile android yang dihubungkan dengan database dan server website Unipdu Jombang yang dilengkapi dengan notifikasi. Dengan adanya aplikasi ini mahasiswa cukup menerima informasi tersebut melalui perangkat mobile android yang dimilikinya. Mengembangkan website Unipdu menuju aplikasi mobile tidak terlepas dari teknologi Hybrid Application dan Teknologi Google Cloud Message (GCM).

Berdasarkan permasalahan tersebut di atas, maka dapat dirumuskan permasalahan yaitu (1) Bagaimana merancang dan membangun aplikasi mobile android berbasis HTML5 pada website Unipdu Jombang? (2) Bagaimana menerapkan teknologi HTML5 beserta teknologi yang lain agar aplikasi mobile dapat berjalan pada platform android?. Adapun tujuan dari permasalahannya adalah (1) Merancang dan membangun aplikasi mobile pada platform android berbasis HTML5 studi kasus website Unipdu Jombang. (2) Menerapkan teknologi HTML5 beserta teknologi yang lain agar aplikasi mobile dapat berjalan pada platform android.

\section{METODE PENELITIAN}

\section{Teknologi Hybrid Application}

Menurut Pace (2012), hybrid application adalah perpaduan kelebihan yang dimiliki native application dengan mobile web application (HTML5). Native Application adalah aplikasi yang terpasang atau terinstal pada perangkat mobile seperti Android, IOs, WindowsPhone, Symbian, atau Blackberry yang memiliki kelebihan aplikasi berjalan lebih fleksibel dan lebih cepat. Sedangkan mobile web application (HTML5) adalah aplikasi berbasis website yang hanya dapat diakses melalui modern web browser yang sudah mendukung HTML5. Kelebihan hybrid aplication adalah Proses loading dan kinerja lebih cepat dan dapat dijalankan sepenuhnya secara offline seperti aplikasi native.

\section{HTML5}

HTLM5 adalah sebuah bahasa markah untuk menstrukturkan dan menampilkan isi dari WWW (world wide web) sebuah teknologi inti dari internet. HTML5 adalah revisi kelima dari HTML yang pertama kali diciptakan pada tahun 1990. HTML5 merupakan salah satu karya World Wide Web Consortium (W3C) untuk mendefinisikan sebuah bahasa markah tunggal yang dapat ditulis dengan cara HTML ataupun XHTML. Salah satu kelebihan dari HTML5 adalah mendukung untuk penyimpanan secara offline. 


\section{Teknologi Google Cloud Messaging (GCM) for Android}

Diambil dari situs resminya http://developer.android.com/google/gcm/i ndex.html, Google Cloud Messaging (GCM) untuk Android adalah layanan yang memungkinkan untuk mengirim data / pesan dari server ke perangkat Android, atau sebaliknya untuk menerima data / pesan dari perangkat ke server pada koneksi yang sama. Layanan GCM menangani semua aspek antrian pesan dan pengiriman ke target aplikasi Android yang berjalan pada perangkat target. GCM gratis tidak peduli seberapa besar kebutuhan messaging dan tidak ada kuota. GCM mamiliki Cloud Connection Service (CCS) yang memungkinkan dapat berkomunikasi dengan perangkat Android melalui koneksi XAMPP persisten. Keuntungan utama dari CCS adalah kecepatan, dan kemampuan untuk menerima pesan hulu (yaitu, pesan dari perangkat ke cloud). Berikut adalah arsitektur dari GCM.

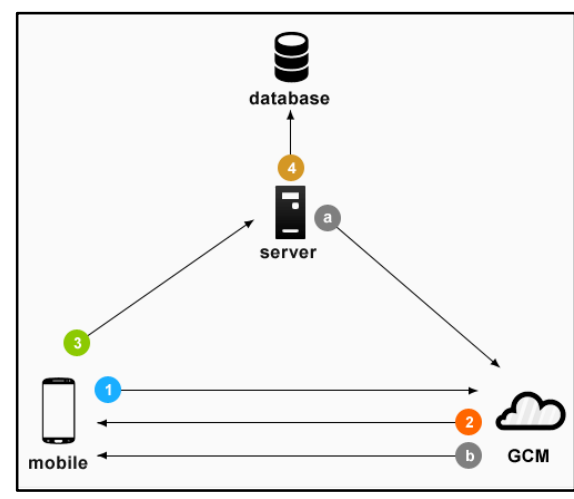

Gambar 1. Arsitektur GCM
Dari gambar di atas dapat dijelaskan bahwa, perangkat mobile harus mendapatkan ID dari GCM dengan melakukan register terlebih dahulu (1) dan (2). Kemudian, ID tersebut akan disimpan pada server (3). Selanjutnya jika terdapat perubahan data pada server atau dengan kata lain admin memposting informasi/ pengumuman, dengan segera server membertahu GCM (a) untuk meneruskan informasi kepada perangkat mobile berupa notifikasi (b). Cara kerja GCM ini yang menjadi landasan dari pengembangan website Unipdu ke arah mobile android.

\section{HASIL PENELITIAN DAN PEMBAHASAN \\ Perancangan Sistem}

Perancangan sistem yang akan dibangun mengadopsi dari Hybrid Application yang saat ini merupakan hal baru dalam dunia teknologi. Hybrid Application sangat cocok digunakan untuk mengembangkan layanan yang ada di website Unipdu Jombang. Gambar di bawah ini menunjukkan gambaran umum dari aplikasi yang akan dibangun.

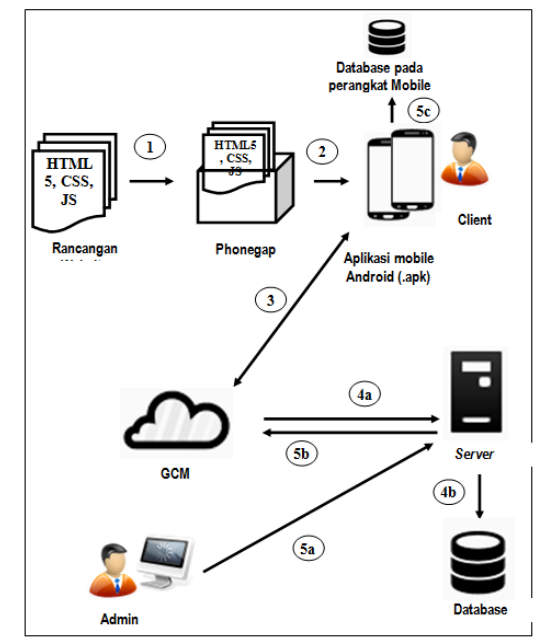

Gambar 2. Gambaran Umum sistem yang akan dibangun

Perangkat lunak pada server yaitu web server yang ditangani oleh script PHP dan database MySQL dengan sistem hosting internet. Aplikasi di sisi server berfungsi untuk menangani koneksi client yang berbasis platform android. 
Setiap inputan dari calon mahasiswa baru dan admin fakultas akan ditangani dan dilayani oleh web server. Perangkat lunak pada client dibuat menggunakan platform android. Aplikasi ini akan dipasang di handphone client yang berfungsi untuk menerima notifikasi layanan informasi website Unipdu Jombang. Gambar 3 di bawah ini menerangkan perancangan sistem.

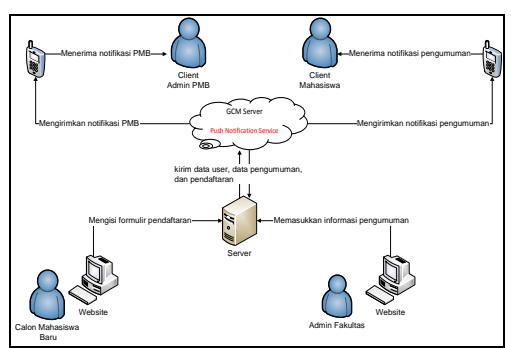

Gambar 3. Alur Sistem yang akan dibangun

\section{Perancangan Database}

Karena dikembangkan dari sistem yang sudah ada, maka terdapat beberapa tabel yang diambil dari sistem sebelumnya. Gambar di bawah adalah hasil gabungan dari perancangan database sistem yang diusulkan. Tabel dengan tanda warna biru adalah tabel dari sistem yang diusulkan.

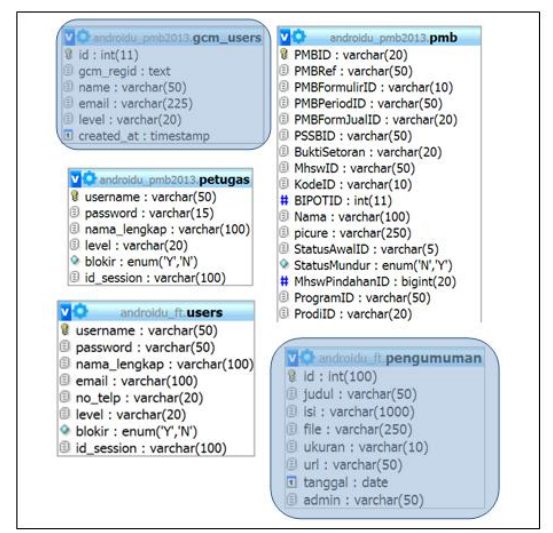

Gambar 4. Perancangan Database

\section{Perancangan Interface}

Berikut adalah tampilan menu dari aplikasi mobile yang akad dibangun. Terdapat sembilan menu utama seperti tampak pada gambar di bawah ini.

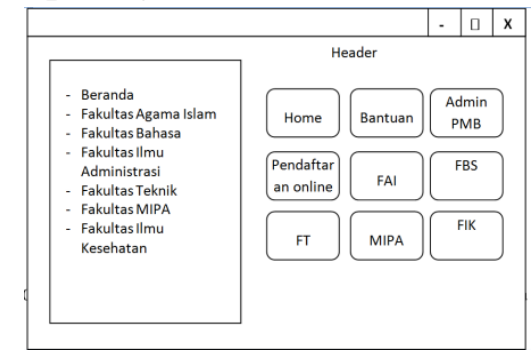

Gambar 5. Perancangan Interface

\section{Implementasi Antatmuka}

Implementasi antarmuka sistem merupakan implementasi hasil dari desain yang telah dirancang sebelumnya. Berikut adalah implementasi antarmuka aplikasi mobile system informasi website unipdu yang dilengkapi dengan fitur notifikasi

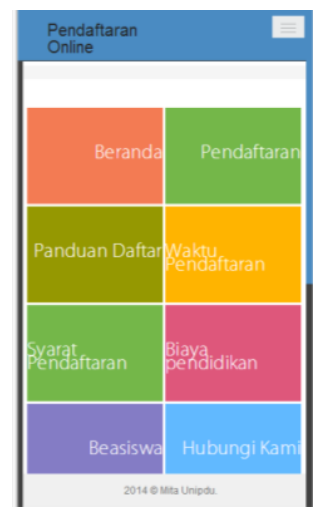

Gambar 6. Halaman pendaftaran online

\section{KESIMPULAN DAN SARAN}

Berdasarkan hasil analisis masalah hingga perancangan, dapat ditarik kesimpulan bahwa teknologi hybrid application dapat digunakan untuk mengambangkan website Unipdu Jombang ke arah mobile android yang dilengkapi dengan notifikasi (pemberitahuan). Mahasiswa dapat dengan mudah mendapatkan informasi dari website 
Unipdu tanpa harus berkunjung ke website secara langsung.

Sedangkan saran yang dapat penulis usulkan adalah bahwa paper ini dibuat dengan maksud keinginan penulis untuk berbagi ilmu pengetahuan. Dari hasil karya tulis ilmiah ini diharapkan pembaca dapat memahami isi dan menganalisis kekurangan di dalamnya. Penulis menyarankan agar penerapan hybrid application ini tidak hanya pada platform Android saja, namun mencakup platform yang lain seperti Windows Phone, iPhone, Blackberry dan lain sebagainya.

\section{DAFTAR PUSTAKA}

Budiyanto, Utomo. (2011). Rancang Bangun Aplikasi Mobile Dosen Penasihat Akademik : Studi Kasus Universitas Budi Luhur Jakarta. Jurnal TELEMATIKA MKOM, 3, (2), 26-29.

Ganefi, Robi. (2012). Pembangunan Aplikasi Mobile Jejaring Sosial Kampus Online Unikom Berbasis Android,. Skripsi pada Jurusan Teknik Informatika Universitas Komputer Indonesia Bandung : tidak diterbitkan.

Hernita. Membuat sendiri Aplikasi Web Mobile menggunakan jQuery Mobile. Yogyakarta: C.V Andi Offset, 2013.

Khafidli, Firgiawan. Trik Menguasai HTML5 CSS3 PHP Aplikatif. Yogyakarta: Lokomedia, 2011.

URL :

http://developer.android.com/google/ gcm/index.html. 19 Oktober 2013.
URL :

http://bisakomputer.com/notepadtext-editor-keren-serba-guna/, 29

Desember 2013.

URL :

www.oracle.com/technetwork/java/JavaS E/downloads/index.html, 04 Desember 2011. 